Original Article

\title{
Effects of complex rehabilitation training on low back strength in chronic low back pain
}

\author{
Jaeyong Park, PhD ${ }^{1)}$, Jung Chul Lee, $\mathrm{PhD}^{2)^{*}}$ \\ 1) Institute of Sports Health Science, Sunmoon University, Republic of Korea \\ 2) Department of Exercise Prescription, Dongshin University: 185 Geonjae-ro, Naju, \\ Jeonnam 520-714, Republic of Korea
}

\begin{abstract}
Purpose] The purpose of this study was to assess the effects of complex rehabilitation training on chronic low back pain. [Subjects and Methods] Complex rehabilitation training for lumbar isometric muscle strength was conducted for 12 weeks for males $(n=10)$ and females $(n=10)$ with chronic low back pain, who were aged in their 30s. [Results] Isometric strength of lumbar extension was increased post-test, and significant differences were found between males and females, at MedX angle of 0,48, and 60. [Conclusion] This study showed that complex rehabilitation training had a beneficial effect on the muscle strength of lumbar extension in patients with chronic low back pain.

Key words: Complex rehabilitation exercise, Lumbar isometric muscle strength, Chronic low back pain
\end{abstract}

(This article was submitted May 13, 2016, and was accepted Jul. 21, 2016)

\section{INTRODUCTION}

The vertebral column is a set of unstable joints, which is involved in a variety of movements, including extension, flexion, right-left bending, and trunk rotation ${ }^{1)}$. Because of its unstable structure, it is involved in many problems related to orthopedic diseases. Prior research has them reported that about $80 \%$ of the global population has lasting complained of back pain or had a history of back pain, and about $20 \%$ of complained of chronic low back pain (CLBP) over 6 months ${ }^{2,3)}$. Since people aged (30 to 50) have a high prevalence of CLBP, it is also becoming a socially and economically significant problem, and it occurs mostly in women aged 40 or older $^{4}$. LBP can be categorized into acute (shorter than 3 months) and chronic ( 3 months or longer) by its duration. In LBP, two of the most frequent types of pain are spondylogenic pain, caused by the vertebral column and its appendicular structures, and neurogenic pain caused by problems in muscle-controlling nerves ${ }^{5)}$. These types of pain are caused by the paravertebral muscles and other types of muscles failing to provide vertebral stability, weakened vertebral bodies, disks, or ligaments between vertebral bodies, or imbalance between the lumbar extensor and flexor muscles ${ }^{6)}$. When imbalance between the abdominal muscles of the trunk and extensor muscles occurs, it triggers LBP and reduces the stability of the lumbar segments ${ }^{7}$.

In general, LBP can be treated surgically or non-surgically. Less than 5\% of all cases actually require surgical therapy, and application of non-surgical therapy alone can reduce pain and restore the functions of the lumbar spine ${ }^{8)}$. In the 1980 s, the main cause of LBP was believed to be weakness of the muscles supporting the vertebral column; therefore, application of active rehabilitation exercise program to improve muscular and physical strength was considered the most ideal gold-standard for patients with $\mathrm{CLBP}^{9,10}$. However, since recent studies have reported that stability of the vertebral segments plays an important role in the mechanisms underlying LBP, rehabilitation exercises based on lumbar stability, or core stabilizer exercises, which can minimize instability of the vertebral segments and eventually decrease LBP, is actively being used to treat $\mathrm{LBP}^{11,12)}$. Characteristically, such rehabilitation exercise not only strengthens the muscles around the spine and pelvis, including the abdomen, but also activates proprioception when the body makes dynamic movements. It is also considered a

\footnotetext{
*Corresponding author. Jung Chul Lee (E-mail: channel365@hanmail.net)

(C)2016 The Society of Physical Therapy Science. Published by IPEC Inc.

This is an open-access article distributed under the terms of the Creative Commons Attribution Non-Commercial No Derivatives (by-nc-nd) License $<$ http://creativecommons.org/licenses/by-nc-nd/4.0/>.
} 
Table 1. Physical characteristics of the subjects

\begin{tabular}{lcccc}
\hline Group & Age (years) & Height $(\mathrm{cm})$ & Weight $(\mathrm{kg})$ & BMI $\left(\mathrm{kg} / \mathrm{m}^{2}\right)$ \\
\hline Female $(\mathrm{n}=10)$ & $34.4 \pm 2.8$ & $163.2 \pm 2.7$ & $53.0 \pm 4.1$ & $20.1 \pm 1.8$ \\
Male $(\mathrm{n}=10)$ & $35.3 \pm 2.9$ & $176.6 \pm 3.0$ & $72.8 \pm 2.6$ & $23.3 \pm 0.7$ \\
\hline
\end{tabular}

BMI: body mass index

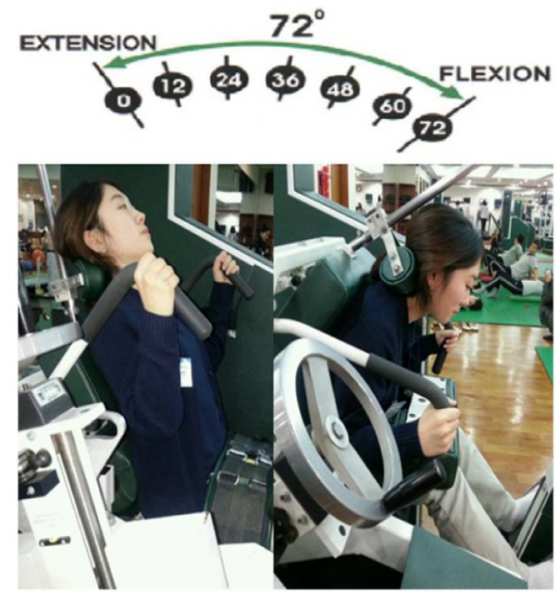

Fig. 1. Equipment used for the isometric muscular strength test

therapeutic element playing a crucial role in maximizing body coordination and lumbar stability through inter-neuromuscular facilitation ${ }^{13)}$. However, Park and colleagues ${ }^{14)}$ reported that the use of a simple lumbar stabilization exercise program, focusing on strengthening the isolated local muscles of the vertebral segments, as a rehabilitation exercise method for patients with CLBP, would not ease LBP and restore vertebral functions. Therefore, a strong correlation between muscular fitness factors and neuromuscular activation in reducing LBP and achieving functional restoration may be suggested. Renkawitz et al. ${ }^{11)}$ reported a strong correlation between restoration of muscular function in global muscles and deep trunk muscles and neuromuscular activation in LBP treatment. In other words, the complementation of two types of therapy may reduce pain, support mobility of the vertebral joints, and restore the muscular functions of the spine. In this respect, rehabilitation exercise is very important for patients with LBP. Cailliet ${ }^{15)}$ reported that rehabilitation exercise could play an important role in restoring tissues by actively extending tendons, ligaments, and joint membranes of joint tissues to facilitate blood circulation as well as improve muscular strength and flexibility.

Many studies have conducted exercises for improving each of the muscular functions, or lumbar stabilization exercise for patients with $\mathrm{CLBP}^{16,17)}$. However, there has been little research on the application of both lumbar stabilization exercises and an active muscular fitness program in a mixed type of rehabilitation exercise. A study of the inter-group differences following the application of a complex rehabilitation program for both males and females would be significant for the development of a universal LBP therapy and an effective rehabilitation exercise program.

This study aimed to determine the effects of a rehabilitation exercise program combining muscular fitness exercise and lumbar stabilization exercise on the lumbar isometric muscular strength (IMS) of both male and female patients with CLBP in their 30s, the age group participating most actively in socio-economic activities.

\section{SUBJECTS AND METHODS}

Twenty individuals, 10 males and 10 females, who visited the J Oriental Medical Hospital in Seoul participated in this study. The participants were patients with CLBP who had had LBP for over 3 months and were receiving general oriental therapy. Those with severe cardiovascular disease, those who could not walk, or those with symptoms of spinal tumor, spinal or disk infection, inflammatory disease, mental illness, or neurological disorder accompanied by motor disturbance were excluded. Before conducting this experiment, only those who understood the purpose of this study, and indicated their active intention to participate in the experiment, after they had listened to explanation on the information and procedure of the experiment were included in the study. This study received approval from the Institutional Review Board (IRB) of Dongshin University on April 27, 2014 (IRB NO: 201401-BM-006-02). The participants' physical characteristics are shown in Table 1.

Figure 1 shows the IMS measurement system used to measure the lumbar extensor strength machine (MedX, Ocala, FL, USA). To assess the lower back and extensor strength, the maximum isometric extensor strength was measured at lumbar 
Table 2. The exercise program performed by the patients with CLBP

\begin{tabular}{|c|c|c|c|c|}
\hline \multirow[t]{2}{*}{ Phase } & \multicolumn{4}{|c|}{ Complex rehabilitation program } \\
\hline & & Type & rep/set (week) & Consideration \\
\hline \multirow[t]{2}{*}{$\begin{array}{l}\text { AP } \\
\text { (Week 1-4) }\end{array}$} & MS & $\begin{array}{l}\cdot \text { Leg flexion/extension } \\
\cdot \text { Dumbbell biceps curl } \\
\cdot \text { Dumbbell triceps extension } \\
\cdot \text { Calf raise } \\
\cdot \text { Lat pull down }\end{array}$ & $7-10$ reps $/ 2$ sets & \multirow{2}{*}{$\begin{array}{l}\text { Non-weight bearing } \\
\text { Open kinetic chain exercise } \\
\text { Exercise in range without pain } \\
\text { Low back flexion and extension to minimize } \\
\text { Frequency and intensity of control, depending } \\
\text { on fitness level } \\
\text { Continuous supervision } \\
\text {. Ice massage after exercise }\end{array}$} \\
\hline & ST & $\begin{array}{l}\text { Quadruped arm/leg lifts with bracing } \\
\cdot \text { Gluteal squeezes } \\
\cdot \text { Pelvic tilt }\end{array}$ & $\begin{array}{l}7-10 \text { reps } / 2 \text { sets: } \\
7-10 \text { reps with } \\
5-7 \text { s hold }\end{array}$ & \\
\hline \multirow[t]{2}{*}{$\begin{array}{l}\text { IP } \\
\text { (Week 5-8) }\end{array}$} & MS & $\begin{array}{l}\cdot \text { Medx exercise (isotonic) } \\
\cdot \text { Crunch machine } \\
\cdot \text { Leg press } \\
\cdot \text { Supine squat (non-weight bearing) } \\
\cdot \text { Multi-hip (adduction, abduction, flexion, } \\
\text { extension) }\end{array}$ & $\begin{array}{l}7-10 \text { reps } / 3 \text { sets: } \\
\text { Medx } 15 \text { reps } 11 \text { set }\end{array}$ & \multirow{2}{*}{$\begin{array}{l}\text { Closed kinetic chain exercise } \\
\text { Eccentric exercise for strength enhancement } \\
\text { Return to adaptation phase, if pain occurred } \\
\text { Prohibit from overloading and over-repetition } \\
\text { Recommendation of minimal bed rest } \\
\text { Recommendation of continued independent } \\
\text { ambulation. } \\
\text { Avoid to high impact exercise such as running } \\
\text {. Ice massage after exercise }\end{array}$} \\
\hline & ST & $\begin{array}{l}\text { Hip rotation exercise with elastic band } \\
\cdot \text { Superman crunch on Gym-ball } \\
\text { - Side bridge on floor }\end{array}$ & $\begin{array}{l}7-10 \text { reps } / 2 \text { sets: } \\
7-10 \text { reps with } \\
5-10 \text { s hold } \\
\end{array}$ & \\
\hline \multirow{2}{*}{$\begin{array}{l}\text { MP } \\
\text { (Week 9-12) }\end{array}$} & MS & $\begin{array}{l}\cdot \text { Medx isotonic exercise } \\
\cdot \text { Standing squat (weight bearing) } \\
\cdot \text { Push-up } \\
\cdot \text { Dumbbell lateral shoulder raise }\end{array}$ & $\begin{array}{l}\text { 10-12 reps/ } \\
3 \text { sets: } \\
\text { Medx } 15 \text { reps } 1 \text { set }\end{array}$ & \multirow{2}{*}{$\begin{array}{l}\text { Weight-bearing exercise } \\
\text { Functional training, including agility } \\
\text { Light jogging } \\
\text { Continuous exercise-recommendatio }\end{array}$} \\
\hline & ST & $\begin{array}{l}\cdot \text { PNF D1-D2 } \\
\cdot \text { Side bridge on Gym-ball } \\
\cdot \text { Reverse curl with Gym-ball } \\
\cdot \text { Superman position on Gym-ball } \\
\cdot \text { Prone pull -ins on Gym-ball }\end{array}$ & $\begin{array}{l}7-10 \text { reps } / 3 \text { sets: } \\
7-10 \text { reps with } \\
5-10 \text { s hold }\end{array}$ & \\
\hline
\end{tabular}

CLBP: chronic low back pain; AP: adaptation phase; IP: improvement phase; MP: maintenance phase; MS: muscular strength; ST: stabilization; PNF D1-D2: proprioceptive neuromuscular facilitation diagonal pattern 1-diagonal pattern 2

* Intensity=1 RM (repetition maximum) 50-80\% (measurement of isotonic or dynamic strength); Type=circuit training; Rest=30 s/set

joint flexion angles of $0,12,24,36,48,60$, and $72^{\circ}$. All patients received a detailed explanation of the experimental procedure in advance, were checked for LBP, and were warned of possible accidents during the test or exercise. The participants' thighs and lower limbs were fixed with knee, thigh, and pelvic restraints, and the foot board to prevent mobilization of leg strength during the lumbar extension strength measurement. Beginning from the lumbar flexion of $72^{\circ}$, the participants were asked to extend their waist gradually upon the tester's order, with reference to pain and restricted joint angles, and to maintain the maximum muscular strength for 1-2 seconds when the maximum strength was exerted the upper resistance pad for 2-3 seconds, to measure extension.

The rehabilitation exercise program in this study was composed of warm-up, main exercise, and cool-down, and was conducted in three, 60-minute sessions a week. The program had three stages, conditioning, improvement, and maintenance phases, and was a revised and complemented version of the complex rehabilitation exercise program developed by Park and colleagues $^{14)}$. Table 2 shows the exercise type, frequency, intensity, time, and considerations of each phase.

SAS ver. 9.2 statistical program was used to compute the descriptive statistics of each item. The paired t-test was carried out to investigate gender differences before and after the intervention. Analysis of covariance (ANCOVA) was performed with prior values set as covariates to examine gender differences according to experimental treatment. When inter-group differences were found, a post-test was performed using the least squares method (LSM). The significance level ( $\alpha$ ) for testing the hypotheses of this study was 0.05 .

\section{RESULTS}

The differences in IMS before and after the intervention are shown in Table 3. There were increases in IMS at every angle for both males and females, and there were statistically significant differences.

The gender differences following experimental procedure as a main effect were statistically significant in IMS at lumbar extensor strengths of 0,48 and $60^{\circ}$. To detail the differences, LSM values are shown in Tables 4,5 and 6 . LSM of IMS at the angle of $0^{\circ}, 48^{\circ}$ and $60^{\circ}$ by gender, as shown in Tables 4,5 and 6 , and they demonstrate that IMS was statistically significantly higher for males than for females. 
Table 3. Changes in IMS presented by gender

\begin{tabular}{clrrl}
\hline variable & Group & \multicolumn{1}{c}{ Pre-test } & Post-test & \multicolumn{1}{c}{$\Delta \%$} \\
\hline \multirow{2}{*}{$0^{\circ}$} & Female & $51.4 \pm 26.8$ & $76.5 \pm 35.8$ & $25.1 \pm 7.0^{* *}$ \\
& Male & $87.3 \pm 18.8$ & $135.4 \pm 15.7$ & $48.1 \pm 10.2^{* *}$ \\
$12^{\circ}$ & Female & $73.7 \pm 33.6$ & $106.2 \pm 51.2$ & $32.5 \pm 8.6^{* *}$ \\
& Male & $123.4 \pm 24.5$ & $179.0 \pm 25.0$ & $55.6 \pm 12.9^{* *}$ \\
$24^{\circ}$ & Female & $95.1 \pm 38.6$ & $123.0 \pm 56.5$ & $27.9 \pm 9.2^{*}$ \\
& Male & $151.9 \pm 35.9$ & $202.1 \pm 21.6$ & $50.2 \pm 14.1^{* *}$ \\
$36^{\circ}$ & Female & $106.7 \pm 44.5$ & $133.5 \pm 56.6$ & $26.8 \pm 6.9^{* *}$ \\
& Male & $173.8 \pm 32.4$ & $219.1 \pm 25.1$ & $45.3 \pm 13.5^{* *}$ \\
$48^{\circ}$ & Female & $117.1 \pm 48.8$ & $142.6 \pm 53.5$ & $25.5 \pm 7.0^{* *}$ \\
& Male & $190.6 \pm 32.6$ & $235.7 \pm 22.3$ & $45.1 \pm 14.0^{*}$ \\
$60^{\circ}$ & Female & $127.0 \pm 45.6$ & $154.4 \pm 55.8$ & $27.4 \pm 7.7^{* *}$ \\
& Male & $194.8 \pm 41.7$ & $246.4 \pm 25.7$ & $51.6 \pm 13.8^{* *}$ \\
$70^{\circ}$ & Female & $137.6 \pm 52.6$ & $161.6 \pm 56.8$ & $24.0 \pm 10.9^{*}$ \\
& Male & $209.6 \pm 30.2$ & $257.5 \pm 35.7$ & $47.9 \pm 11.3^{* *}$ \\
\hline
\end{tabular}

IMS: isometric muscle strength; $\Delta \%$ : percent difference between pre and post; Mean $\pm \mathrm{SD}$; $* \mathrm{p}<0.05,{ }^{* *} \mathrm{p}<0.01$

Table 4. LSM values of lumbar extension IMS at $0^{\circ}$

\begin{tabular}{lrccc}
\hline Group & LSM & F & t-value & Post-hoc \\
\hline Female & $85.3 \pm 9.4$ & $7.61^{* *}$ & $-2.76^{*}$ & Female $<$ Male \\
Male & $126.6 \pm 9.4$ & & & \\
\hline
\end{tabular}

LSM: least squares method; Mean $\pm \mathrm{SD} ;{ }^{*} \mathrm{p}<0.05,{ }^{* *} \mathrm{p}<0.01$

Table 5. LSM values of lumbar extension IMS at $48^{\circ}$

\begin{tabular}{lcccc}
\hline Group & LSM & F & t-value & Post-hoc \\
\hline Female & $165.9 \pm 12.3$ & $5.51^{* *}$ & $-2.35^{*}$ & Female $<$ Male \\
Male & $212.4 \pm 12.3$ & & & \\
\hline
\end{tabular}

LSM: least squares method; Mean $\pm \mathrm{SD} ;{ }^{*} \mathrm{p}<0.05,{ }^{* *} \mathrm{p}<0.01$

Table 6. LSM values of lumbar extension IMS at $60^{\circ}$

\begin{tabular}{lcccc}
\hline Group & LSM & F & t-value & Post-hoc \\
\hline Female & $177.0 \pm 12.1$ & $5.97 *$ & $-2.44^{*}$ & Female $<$ Male \\
Male & $223.8 \pm 12.1$ & & &
\end{tabular}

\section{DISCUSSION}

Low back pain is a typical musculoskeletal disease caused by weakening or disharmony of the inner and outer muscles of the trunk and other tissues (tendons, ligaments, joint membranes, etc.) affecting spinal and pelvic mobility, and stabilization, mainly due to problems with the musculoskeletal structure. In particular, it varies from simple types caused by abnormal biomechanical problems to complex ones caused by a variety of factors, and has various symptoms, thus requiring very complicated therapies ${ }^{18)}$. As a safe method of treating LBP with relatively few side effects and reducing medical expenses, exercise is effective. For this reason, it is believed that the development of a clinically usable rehabilitation exercise program for LBP therapy, is of itself significant. This study aimed to assess the effects of a rehabilitation exercise program composed of IMS exercise and lumbar stabilization exercise on lumbar IMS of the low back of 20 males and females in their 30s, diagnosed with CLBP.

Muscular exercise for strengthening the trunk muscles is a very important intervention for patients with LBP. The normal 
functions of various types of muscles around the vertebral joints can provide stable support and enable smooth dynamic movement of the body ${ }^{19)}$. In a previous study, a lumbar segmental stabilization exercise elicited a statistically significant effect on the in strength of the muscles of the gluteus group ${ }^{20)}$. In another study, aquatic therapy exercise enhanced the low back muscle strength and reduced LBP of elderly females ${ }^{21}$.

This study assessed the lumbar IMS at $0,12,24,36,48,60$, and $72^{\circ}$ to determine the muscular fitness of patients with LBP and found there was a significant improvement across the entire range measured following the performance of the complex rehabilitation program. As for gender differences, males showed significantly greater improvement at 0,48 , and $60^{\circ}$ than females. This gender difference can be considered as a difference in physiological reaction to resistance exercise. In other words, there is no gender difference in muscular strength before puberty; however, in adulthood, females have lower muscular strength than males due to hormonal changes, weight, body composition, muscle mass, and transversal area of muscular fibers ${ }^{22}$. Jackson, Shepherd, and Kell ${ }^{23)}$ reported that resistance exercise performed for 16 weeks reinforced the lumbar muscular strength of middle-aged people with CLBP. Like this study, other prior studies have reported that resistance exercise beginning with low intensity and with a gradually increasing intensity and number of sessions is effective at improving the muscular strength and lowering the rate of repeated injury among in patients with CLBP ${ }^{24}$.

It is considered that muscular function improvement and lumbar stability exercise play important roles in controlling spinal segments and providing stability in the alleviation of $\mathrm{LBP}^{11,12}$. Any prior studies have reported that effective rehabilitation exercise activates functions of the intersegmental muscles, such as the multifidus, rotators, and abdominis muscles, which contribute to the functioning of the spine, improving stability and balance control of the body ${ }^{25}$. Thus, it can be emphasized that scientific verication of an exercise program is crucial for LBP therapy and recurrence. As for prior research concerning specific exercise programs, Park and colleagues ${ }^{14)}$ indicated that an exercise program that simultaneously strengthens the deep abdominal muscles and muscles of the trunk is the most ideal method for maintaining spinal stability and physical balance, and the American College of Sports Medicine (ACSM) ${ }^{26)}$ recommends that it is necessary to perform lumbar and abdominal muscular strength exercises more than once a week, and flexibility exercise for improving the mobility range of vertebral joints for more than three sessions, 10 seconds per session. It is also recommended that priority should be given to simultaneous maintenance of the lower limbs rather than simple reinforcement of muscular strength, and that spinal correction exercise for improving postural balance should be performed in addition to improving lumbar muscular functions.

In conclusion, this study conducted a complex rehabilitation exercise for 20 patients (10 females, 10 males) with CLBP who were in their 30s in 60-minute sessions, 3 times a week for 12 weeks, to determine the changes elicited in lumbar IMS by gender. All patients showed statistically significant improvement in lumbar IMS. Males showed greater improvement than females at the angles of 0,48 , and $60^{\circ}$. Therefore, a 12 -week complex rehabilitation program for muscle strengthening aimed at patients with CLBP appears to be effective at improving lumbar muscular strength.

\section{REFERENCES}

1) Crisco JJ, Panjabi MM, Yamamoto I, et al.: Euler stability of the human ligamentous lumbar spine. Part II: Experiment. Clin Biomech (Bristol, Avon), 1992, 7 : 27-32. [Medline] [CrossRef]

2) Panjabi MM: Clinical spinal instability and low back pain. J Electromyogr Kinesiol, 2003, 13: 371-379. [Medline] [CrossRef]

3) Dugan SA: The role of exercise in the prevention and management of acute low back pain. Clin Occup Environ Med, 2006, 5: 615-632, vi-vii. [Medline]

4) Hicks GE, Fritz JM, Delitto A, et al.: Preliminary development of a clinical prediction rule for determining which patients with low back pain will respond to a stabilization exercise program. Arch Phys Med Rehabil, 2005, 86: 1753-1762. [Medline] [CrossRef]

5) Adams MA, Roughley PJ: What is intervertebral disc degeneration, and what causes it? Spine, 2006, 31: 2151-2161. [Medline] [CrossRef]

6) Danneels LA, Vanderstraeten GG, Cambier DC, et al.: Effects of three different training modalities on the cross sectional area of the lumbar multifidus muscle in patients with chronic low back pain. Br J Sports Med, 2001, 35: 186-191. [Medline] [CrossRef]

7) Jung DE, Kim K, Lee SK: Comparison of muscle activities using a pressure biofeedback unit during abdominal muscle training performed by normal adults in the standing and supine positions. J Phys Ther Sci, 2014, 26: 191-193. [Medline] [CrossRef]

8) Kirkaldy-Willis WH, Burton CV: Managing low back pain, 4th ed. London: Churchill Livingstone, 1992

9) McQuade KJ, Turner JA, Buchner DM: Physical fitness and chronic low back pain. An analysis of the relationships among fitness, functional limitations, and depression. Clin Orthop Relat Res, 1988, (233): 198-204. [Medline]

10) Shirado O, Ito T, Kaneda K, et al.: Concentric and eccentric strength of trunk muscles: influence of test postures on strength and characteristics of patients with chronic low-back pain. Arch Phys Med Rehabil, 1995, 76: 604-611. [Medline] [CrossRef]

11) Renkawitz T, Boluki D, Grifka J: The association of low back pain, neuromuscular imbalance, and trunk extension strength in athletes. Spine J, 2006, 6: 673-683. [Medline] [CrossRef]

12) Aure OF, Nilsen JH, Vasseljen O: Manual therapy and exercise therapy in patients with chronic low back pain: a randomized, controlled trial with 1-year follow-up. Spine, 2003, 28: 525-531, discussion 531-532. [Medline] [CrossRef]

13) Standaert CJ, Weinstein SM, Rumpeltes J: Evidence-informed management of chronic low back pain with lumbar stabilization exercises. Spine J, 2008, 8: 114-120. [Medline] [CrossRef]

14) Park JY, Bae JJ, Lee JC, et al.: The effects of complex rehabilitation exercise program on postural balance in male with chronic LBP. J Sport Leis Stud, 2012, 48: $773-782$.

15) Cailliet R: Low back pain syndrome, 5th ed. Philadelphia: FA DAVIS, 1995 
16) van Tulder MW, Koes B: Malmivaara: outcome of non-invasive treatment modalities on back pain: an evidence-based review. Eur Spine J, 2006, 15: 64-81. [CrossRef]

17) Hayden JA, van Tulder MW, Tomlinson G: Systematic review: strategies for using exercise therapy to improve outcomes in chronic low back pain. Ann Intern Med, 2005, 142: 776-785. [Medline] [CrossRef]

18) Weiner SS, Nordin M: Prevention and management of chronic back pain. Best Pract Res Clin Rheumatol, 2010, 24: 267-279. [Medline] [CrossRef]

19) Moon HJ, Choi KH, Kim DH, et al.: Effect of lumbar stabilization and dynamic lumbar strengthening exercises in patients with chronic low back pain. Ann Rehabil Med, 2013, 37: 110-117. [Medline] [CrossRef]

20) Jeong UC, Sim JH, Kim CY, et al.: The effects of gluteus muscle strengthening exercise and lumbar stabilization exercise on lumbar muscle strength and balance in chronic low back pain patients. J Phys Ther Sci, 2015, 27: 3813-3816. [Medline] [CrossRef]

21) Han GS, Cho MH, Nam GT, et al.: The effects on muscle strength and visual analog scale pain of aquatic therapy for individuals with low back pain. J Phys Ther Sci, 2011, 23: 57-60. [CrossRef]

22) Mittendorfer B, Rennie MJ: Swings and roundabouts for muscle gain and loss: differences between sexes? J Appl Physiol 1985, 2006, 100: 375-376. [Medline] [CrossRef]

23) Jackson JK, Shepherd TR, Kell RT: The influence of periodized resistance training on recreationally active males with chronic nonspecific low back pain. J Strength Cond Res, 2011, 25: 242-251. [Medline] [CrossRef]

24) Carpenter DM, Nelson BW: Low back strengthening for the prevention and treatment of low back pain. Med Sci Sports Exerc, 1999, 31: 18-24. [Medline] [CrossRef]

25) Jemmett RS: Rehabilitation of lumbar multifidus dysfunction in low back pain: strengthening versus a motor re-education model. Br J Sports Med, 2003, 37: 91-94. [Medline] [CrossRef]

26) America College of Sports Medicine: ACSM's guidelines for exercise testing and prescription. Philadelphia: Lippincott Williams \& Wilkins, 2010. 